\title{
TRAUMA SEM FRONTEIRAS
}

\section{TRAUMA WITHOUT FRONTIERS}

\section{ECBC Mario Mantovani*}

Uma grande notícia é oferecida neste momento pois o Brasil, uma vez mais, torna-se o foco de atenção com o quarto Congresso conjunto entre a Sociedade Panamericana de Trauma (SPT) e a Sociedade Brasileira de Atendimento Integrado ao Traumatizado (SBAIT) e, neste ano, acrescido do Congresso Brasileiro das Ligas do Trauma (CoLT). Será o XXI Panamerican Congresso of Trauma (SPT), VIII Congresso da Sociedade Brasileira de Atendimento Integrado ao Traumatizado (SBAIT) e X Congresso Brasileiro das Ligas do Trauma (CoLT). Este evento será realizado em Campinas - SP, de 19 a 22 de Novembro de 2008, onde se discutirão assuntos que certamente promoverão melhor atendimento à doença trauma em nosso País.

Destaque-se a importância da participação de SPT que trará toda a sua experiência e conhecimentos, através da participação dos convidados estrangeiros que ministrarão cursos, aulas, conferências e mesas redondas, expondo sempre o ponto de vista prático, como eles fazem e como enfrentam seus problemas no atendimento da doença negligenciada da idade moderna, que é o trauma.

O Congresso internacional contará com a presença de conceituados cirurgiões e outros profissionais que atuam na América do Norte, Central e do Sul, sendo 66 palestrantes internacionais convidados que já confirmaram sua presença, onde se discutirão e buscarão soluções para a prevenção e organização de sistemas de saúde para atendimento dos traumatizados, como um dos assuntos relevantes a serem tratados.

Cada Congresso tem características específicas. Este, especialmente, promoverá a capacitação de profissionais da área de saúde que atuam na assistência do traumatizado com cursos e apresentações de pesquisas na área de trauma. Serão discutidos temas nas áreas de prevenção, pré-hospitalar e hospitalar, terapia intensiva e urgências cirúrgicas não traumáticas, que fazem parte do cotidiano do cirurgião do trauma que atua nas unidades de emergência. Este Congresso Internacional reunirá experiências de profissionais de 21 países pois, embora a realidade do trauma seja a mesma, cada país tem suas características epidemiológicas próprias, predominando sempre a violência (homicídios e suicídios) e os eventos de trânsito com veículos automotores, como causas externas mais importantes, onde teremos oportunidade de conhecer e trocar experiência com outros países que apresentam programas efetivos para o controle da violência.

Por outro lado, a participação das Ligas do Trauma (CoLT) será intensa, onde os alunos terão oportunidade de participar de um Congresso internacional com duas sociedades importantes das Américas (SPT e SBAIT) e apresentarão aos estagiários esse movimento acadêmico que, ao completar dez anos de atuação integrada, já está consolidado em nosso meio. Assim, a possibilidade de reunir num período de cinco dias, profissionais acadêmicos de várias cidades do Brasil e de outros países, permitirá que diversos assuntos sobre trauma e emergência e áreas afins sejam discutidos, gerando avanços na área de ensino, assistência, pesquisa e gerenciamento em trauma, despertando mais o interesse pela área, contribuindo para a formação do futuro cirurgião do trauma e emergência, de alta qualidade e competência, na altura da necessidade do nosso país.

O Congresso, na área de atendimento pré-hospitalar $(\mathrm{APH})$, realizará um encontro dos Coordenadores dos Sistemas de Urgência, Emergência e Planejamento em Catástrofes dos representantes dos Ministérios da Saúde de 16 países da América Latina. Serão discutidos temas como a organização de sistemas para o traumatizado para a América Latina, desde o APH, onde serão confrontados os sistemas europeu e americano com as realidades de cada país, inclusive o Brasil, até o atendimento hospitalar. Durante todo o Congresso, haverá salas com temas de APH, desde o atendimento em catástrofes até condutas, procedimentos e organização de sistemas, além de trabalhos e pôsteres nas sessões científicas do Congresso e apresentação de simulações de acidente em desastre. Participarão destas apresentações profissionais estrangeiros que viveram o atendimento no World Trade Center-NY, no terremoto do Irã e no furacão Katrina, além de aulas práticas com pessoal especializado que atendem nas rodovias e transporte aeromédico paulistas.

A SBAIT, por sua vez, sente-se honrada em ser a promotora nacional que, a cada dois anos, realiza seu Congresso de Cirurgia do Trauma e Emergência, revezando anualmente com o Colégio Brasileiro de Cirurgiões, parceiro de todas as horas, participando com entusiasmo como Especialidade que convive intensamente com outras, todas apoiadas na sua formação básica de cirurgia geral, sem qualquer disputa, conflito ou competição. Na qualidade de sociedade científica especializada, cuida da cirurgia do trauma racionalmente como plenário e tribuna do aprimoramento e capacitação do especialista para o enfrentamento da doença trauma e da sobrevivência profissional de seus membros que, no desempenho das suas funções, abarcam toda a área da cirurgia geral e do atendimento do trauma e das emergências cirúrgicas não traumáticas que requerem, para tanto, um médico altamente capacitado para este fim no atendimento pré hospitalar, hospitalar (em hospitais gerais ou sistemas de trauma) e na reabilitação. Este especialista capacitado tem como máxima que a vítima do trauma é um paciente especial pela gravidade da doença, pela permanência hospitalar prolongada e caríssima e, muitas vezes, com seqüelas. Para enfrentar tudo isto, o cirurgião do trauma se desdobra e necessita de aprimoramento contínuo com ótima formação acadêmica e científica para 
atuar, tanto no suporte básico quanto no suporte avançado de vida, no seu dia a dia, pois o paciente crítico deve ser atendido na hora certa, levado ao hospital certo e, principalmente, para o médico certo, pois não é qualquer cirurgião que tem o treinamento exigido que ultrapassa, de longe, a sua formação cirúrgica básica. Assim, a SBAIT vem desempenhando suas funções com todas as forças e entusiasmo para que sempre possa ter voz forte e alta representação, principalmente no ponto crítico destacado pelo Ministério da Saúde que é o atendimento das urgências e emergências.

A Sociedade existe de fato e de direito há vinte e cinco anos e este Congresso internacional vem demonstrar que a Especialidade fica cada vez mais respeitada e reconhecida como excelente parceira das sociedades irmãs e legítima representante e principal interlocutora no atendimento e tratamento da doença trauma em nosso país. Este especial encon- tro discutirá e apresentará soluções para os problemas atuais mundiais e brasileiros ligados ao trauma e emergência e a SBAIT participará com coragem sobre a questão das definições políticas governamentais, oferecendo novas perspectivas, direcionando discussões sobre assuntos polêmicos sempre de forma estimulante e generosa, no corrente status da arte e ciência da Cirurgia do Trauma e Emergência

\footnotetext{
* Mario Mantovani - Professor Titular e Chefe da Disciplina de Cirurgia do Trauma do Departamento de Cirurgia da Faculdade de Ciências Médicas da Universidade Estadual de Campinas. Presidente da Sociedade Brasileira de Atendimento Integrado ao Traumatizado. Orientador Nacional das Ligas do Trauma no Brasil. Presidente do XXI Panamerican Congress Of Trauma, VIII Congresso da Sociedade Brasileira de Atendimento Integrado ao Traumatizado (SBAIT) e X Congresso Brasileiro das Ligas do Trauma (CoLT)
} 